\title{
Inferior retinotomy and silicone oil tamponade for recurrent inferior retinal detachment and grade C PVR in eyes previously treated with pars plana vitrectomy or scleral buckle
}

\author{
Raffaele Mancino ${ }^{*}$, Francesco Aiello, Elena Ciuffoletti, Emiliano Di Carlo, Angelica Cerulli and Carlo Nucci
}

\begin{abstract}
Background: One of the most challenging problems in vitro-retinal surgery is the recurrence of retinal detachment in the context of high-grade proliferative vitreoretinopathy (PVR). The aim of our retrospective study was to assess the surgical outcomes of pars plana vitrectomy, $180^{\circ}$ inferior retinotomy and silicone oil tamponade combined with phacoemulsification and IOL implantation for recurrent inferior retinal detachment with grade C PVR in phakic eyes. The study was carried out at tertiary referral centre - University Hospital of Rome "Tor Vergata".

Methods: Retrospective analysis of 33 eyes affected by recurrent inferior retinal detachment and grade C PVR after primary encircle scleral buckling (SB group - 12 eyes), or pars plana vitrectomy (PPV group - 21 eyes). All patients subsequently underwent PPV and silicone oil tamponade at our Institution. The first outcome measure was retinal reattachment, and second outcomes were reoperation rates, best-corrected visual acuity (BCVA) and postoperative complications.

Results: All patients in the SB group and 19 (90 \%) patients of the PPV group achieved retinal reattachment. Final BCVA was better in the SB group $(p=0.045)$. Two eyes in the PPV group required a third vitrectomy with heavy silicone oil tamponade. Postoperative complications included silicone oil in a deep anterior chamber (3 eyes in each group), untreatable hypotony in 1 eye in the PPV group (that led to enucleation due to phthisis bulbi), and elevated intraocular pressure in 3 patients (2 eyes in the PPV group).

Conclusions: Phacoemulsification with IOL implant, PPV with silicone oil tamponade associated with $180^{\circ}$ inferior retinotomy may lead to better anatomical success in patients who have previously undergone SB procedure for inferior retinal detachment repair compared with eyes that underwent a primary PPV.
\end{abstract}

Keywords: Recurrent retinal detachment, Scleral buckle, Pars plana vitrectomy, Inferior retinotomy, Silicone oil tamponade

\footnotetext{
* Correspondence: mancino@med.uniroma2.it

Ophthalmology Unit, Department of Experimental Medicine and Surgery,

University of Rome "Tor Vergata", Via Montpelier 1, 00133 Rome, Italy
} 


\section{Background}

In 1979, Machemer described how to perform a therapeutic cut of the retina, achieving retinotomy during pars plana vitrectomy (PPV) [1]. He also defined indications for retinotomy, particularly when proliferative vitreoretinopathy (PVR) is responsible for circumferential/axial retinal traction [2]. Over the years, these procedures have been combined in many studies [3-11] culminating in the recent multicentre Silicone Oil Study [12-15]. Blumenkranz et al. [13] suggested that retinotomy is essential in eyes which have undergone primary PPV for retinal detachment as they frequently develop post-operative PVR $[3,6,7]$. One of the most challenging surgical problems is the inferior retinal detachment (RD), due to the absence of an optimal intravitreal tamponade agent. This is due to the inadequate surface tension and consequent reduced tamponade effect on the inferior part of the retina. In light of this difficulty, PVR can further complicate an inferior redetachment after PPV. Furthermore, the silicone oil tamponade left in the eye during PPV for inferior retinal detachment may lead to the sequestration of retinal epithelium pigment cells over the inferior retina resulting in new PVR [16, 17]. Alternatively a scleral buckle (SB) can in theory offer good support to the retina, however this technique remains technically demanding with an increase in potential intraoperative and postoperative complications [18-20]. The purpose of this study was to investigate surgical and visual outcomes of phacoemulsification with intraocular lens (IOL) implant, PPV with inferior retinotomy extended to 180 degrees, and a silicone oil implant to treat recurrent inferior retinal detachment in those previously treated with PPV compared to SB surgery. The primary outcome was anatomical surgical success, defined as a complete retinal re-attachment at last follow up. Secondary outcomes included visual acuity (VA), VA improvement, the number of subsequent operations required for reattachment and post-operative complications.

\section{Methods}

The Institutional Review Board of the "Tor Vergata" University Hospital approved this audit. The study has been performed in accordance with the ethical standards laid down in the 1964 Declaration of Helsinki and its later amendments. Data was obtained by a retrospective study of the medical records of eyes affected by inferior retinal redetachment subsequent to primary PPV or SB surgery performed for inferior rhegmatogenous RD. Inclusion criteria included the presence of grade C PVR according the Machemer's classification [21], defined as the presence of full thickness rigid retinal folds in one area with heavily condensate vitreous organization. We identified 33 eyes of 33 consecutive patients that underwent primary retinal repair at our Centre or were referred to our Institution for further management after primary RD surgery had failed. All patients underwent the second surgical procedure at our Institution by a single surgeon (RM) between 2008 and 2012. Patients were divided into two groups according to the first RD surgery repair technique; the first group had undergone previous SB surgery (12 eyes of 12 patients), whilst the second group had undergone pars plana vitrectomy (PPV) (21 eyes of 21 patients). All patients in the SB group had received encircling band and circumferential buckle placed at the time of the primary RD repair.

Surgery was performed after informed consent was obtained from all patients. Exclusion criteria were: proliferative diabetic retinopathy, high myopia, penetrating eye injury, uveitis, more than one previous retinal detachment surgery, or with $<12$ months postoperative followup. Eyes that underwent retinotomy less then 180 degrees due to a less severe retinal detachment status were excluded from this study.

Each patient underwent pre- and post-operative complete ophthalmic examination, which included logarithm of the minimum angle of resolution (logMAR), best-corrected visual acuity (BCVA), applanation tonometry, slit lamp biomicroscopy and dilated binocular indirect ophthalmoscopy with scleral depression to evaluate retinal status, and PVR.

Outcome variables included BCVA, retinal reattachment rate at final follow-up, the number of cases requiring reoperation, and postoperative complications. Data were collected at follow-up examination on postoperative day 1, 1 week, 1 month, 3 months, 6 months, 1 year and 2 years post-surgery. The mean time between first surgery and retinal redetachment diagnosis was 14 days (range: 3 to 30 days). BCVA was evaluated separately for each eye with a standard ten-letter logarithmic chart $4 \mathrm{~m}$ [22], ${ }^{28}$. Values of $1.3 \log$ MAR (equivalent to $20 / 400$ Snellen), $1.6 \log$ MAR (20/800) and 2.0 logMAR (20/ 2000) were assigned when the first line of the chart was read at $2 \mathrm{~m}, 1.1 \mathrm{~m}$ and $40 \mathrm{~cm}$ respectively; hand motion at $40 \mathrm{~cm}$ was classified as $3.0 \log$ MAR (equivalent of 20/ 20,000) [23]. Visual loss was classified according to the World Health Organization (WHO) criteria [24]: low vision $=$ BCVA $>0.5$ to $1.3 \operatorname{logMAR}(<20 / 70$ to $20 / 400$ Snellen) (ICD-10 categories $1-2$ ); blindness $=$ BCVA $>1.3$ $\log$ MAR $(<20 / 400)$ (ICD-10 categories 3-5).

\section{Surgery}

All patients were phakic at the time of re-detachment surgery repair. All eyes that had undergone PPV were tamponaded with oil during the first surgery. Observing that all re-detachments occurred between 3 and 30 days after the first surgery, all eyes had silicon oil in the vitreous cavity at the time of secondary re-detachment surgery. Thus, standard $3.0 \mathrm{~mm}$ clear corneal incision phacoemulsification surgery and implantation of a three- 
piece IOL was performed in all eyes to allow an adequate vitreous base shaving, and anterior PVR dissection - as described by Quiram et al. [25] A 23-gauge pars plana vitrectomy was then performed (with silicon oil removal for eyes that had received a previous PPV). A 360-degree scleral depression was then performed to allow complete anterior vitreous base visualization and removal. Perfluorocarbon was used to protect the macula from haemorrhages and to flatten the retina during the procedure [26]. PVR membranes were peeled from the retinal surface using an illuminated pick, retinal spatula or forceps. Full thickness endocautery was used to delimit the inferior 180-degrees of the retina before performing vitrectorassisted relaxing retinotomy. Subsequent posterior retinal turnover was performed to remove subretinal membranes if present, with direct visualization. The retina anterior to the retinotomy was completely removed with the highspeed vitrector to prevent neovascularization due to ischemic stimuli [27]. After flattening the retina with perfluorocarbon liquid. a double concentric pattern of endolaser was applied to the retinotomy edges, followed by direct perfluorocarbon liquid/silicone oil (1000 centistokes)

Table 1 Characteristics of all participants in the study

\begin{tabular}{|c|c|c|c|c|c|c|c|}
\hline Code & First surgical technique & Age (yrs) & Sex & PVR grade & Initial BCVA (logMAR) & Final BCVA (logMAR) & Macular status \\
\hline 01 & SB & 49 & M & $\mathrm{C} 2$ & 3.0 & 0.7 & Detached \\
\hline 02 & SB & 43 & $\mathrm{~F}$ & $\mathrm{C} 1$ & 0.5 & 0.2 & Attached \\
\hline 03 & PPV & 30 & $\mathrm{~F}$ & $\mathrm{C} 2$ & 3.0 & 1.3 & Detached \\
\hline 04 & PPV & 45 & $\mathrm{~F}$ & $\mathrm{C} 1$ & 1.0 & 1.0 & Detached \\
\hline 05 & PPV & 49 & M & $\mathrm{C} 2$ & 0.7 & 1.8 & Detached \\
\hline 06 & PPV & 61 & M & $\mathrm{C} 2$ & 0.7 & 0.7 & Attached \\
\hline 07 & SB & 51 & $\mathrm{~F}$ & $\mathrm{C} 1$ & 0.4 & 0.7 & Attached \\
\hline 08 & PPV & 63 & $\mathrm{~F}$ & $\mathrm{C} 1$ & 0.3 & 0.5 & Attached \\
\hline 09 & PPV & 69 & M & $\mathrm{C} 2$ & 0.2 & 0.1 & Attached \\
\hline 10 & SB & 59 & $M$ & $\mathrm{C} 1$ & 0.7 & 0.6 & Attached \\
\hline 11 & PPV & 70 & M & $\mathrm{C} 1$ & 0.3 & 0.7 & Attached \\
\hline 12 & PPV & 31 & M & $\mathrm{C} 1$ & 0.5 & 0.9 & Attached \\
\hline 13 & PPV & 60 & $F$ & $\mathrm{C} 1$ & 2.0 & 1.0 & Detached \\
\hline 14 & SB & 60 & $F$ & $C 2$ & 1.8 & 0.2 & Detached \\
\hline 15 & SB & 62 & M & $C 2$ & 1.3 & 0.8 & Detached \\
\hline 16 & PPV & 70 & M & $C 2$ & 1.6 & 1.3 & Detached \\
\hline 17 & PPV & 40 & $F$ & $\mathrm{C} 1$ & 1.8 & 0.1 & Detached \\
\hline 17 & SB & 38 & M & $C 2$ & 1.6 & 0.9 & Detached \\
\hline 19 & PPV & 45 & M & $\mathrm{C} 1$ & 1.4 & 0.6 & Detached \\
\hline 20 & PPV & 69 & $F$ & $\mathrm{C} 2$ & 0.3 & 0.2 & Attached \\
\hline 21 & PPV & 71 & M & $C 2$ & 0.7 & 1.8 & Detached \\
\hline 22 & SB & 44 & M & $\mathrm{C} 1$ & 0.3 & 0.5 & Attached \\
\hline 23 & SB & 46 & $F$ & $C 2$ & 1.0 & 0.7 & Attached \\
\hline 24 & PPV & 50 & $F$ & $\mathrm{C} 2$ & 3.0 & 0.1 & Detached \\
\hline 25 & SB & 57 & M & $C 2$ & 0.2 & 0.1 & Attached \\
\hline 26 & SB & 67 & M & $\mathrm{C} 1$ & 0.4 & 0.4 & Attached \\
\hline 27 & PPV & 59 & M & $\mathrm{C} 1$ & 3.0 & 0.2 & Detached \\
\hline 28 & PPV & 66 & $F$ & $C 2$ & 0.9 & 0.7 & Attached \\
\hline 29 & PPV & 70 & M & $\mathrm{C} 1$ & 1.6 & 1.3 & Detached \\
\hline 30 & SB & 70 & M & $C 2$ & 0.6 & 0.4 & Attached \\
\hline 31 & PPV & 71 & M & $\mathrm{C} 1$ & 3.0 & 1.8 & Detached \\
\hline 32 & PPV & 52 & $F$ & $\mathrm{C} 2$ & 1.6 & 0.9 & Detached \\
\hline 33 & PPV & 69 & M & $C 2$ & 3.0 & 1.3 & Detached \\
\hline
\end{tabular}

SB Scleral Buckling, PPV Pars Plana Vitrectomy, M Male, F Female, PVR proliferative vitreoretinopathy, BCVA Best-Corrected Visual Acuity 
exchange to prevent further retina mobilization. In all eyes an inferior iridectomy was performed to prevent pupillary block glaucoma that can arise in pseudophakic eyes after vitrectomy and silicone oil injection as previously described [28, 29]. No position restrictions were given postoperatively.

\section{Statistics}

Mean, standard deviation (SD), median, $25 \%$ and $75 \%$ quartiles, minimum and maximum values were computed for all variables. For continuous variables, data was compared using the Student's t-test or paired t-test. For categorical variables, comparison between groups was performed using the Chi-square or Fisher exact tests. Significance was set at $p<0.05$.

\section{Results}

Thirty-three eyes of 33 consecutive patients underwent vitreoretinal surgery: 20 males (60.6\%) and 13 females (39.3 \%) with recurrent inferior RD and grade C PVR. The mean age was $56.2 \pm 12.3( \pm \mathrm{SD})$ years (range: 30 to 71 years). Thirty-one $(93.9 \%)$ patients were Caucasian, 1 (3\%) African and 1 (3\%) Asian. All patients were admitted to the Department of Vitreoretinal Surgery of the University of Rome "Tor Vergata" between January 2008 and June 2012 for secondary RD surgery repair. The mean follow-up period was 42 months (range: 12 to 60 months). Baseline characteristics of the two groups were homogeneous with no significant statistical difference between groups in terms of age, gender, PVR stage, initial BCVA and macular status (Tables 1 and 2). All patients were phakic. At the time of surgery, 12 patients $(36.4 \%)$ had previously undergone encircling scleral

Table 2 Characteristics of groups previously treated with scleral buckling (SB) or pars plana vitrectomy (PPV)

\begin{tabular}{llll}
\hline Characteristic & SB group (12) & PPV group (21) & P \\
\hline $\begin{array}{l}\text { Age in years (mean } \pm \text { SD) } \\
\text { Sex (No. of male/ }\end{array}$ & $53.83 \pm 10.15$ & $57.61 \pm 13.40$ & $0.404^{\mathrm{a}}$ \\
$\begin{array}{l}\text { No. of female) } \\
\text { Grade C PVR (No. of stage }\end{array}$ & $8 / 4$ & $12 / 9$ & $0.719^{\mathrm{b}}$ \\
$\begin{array}{l}\text { 1/No. of stage 2) } \\
\begin{array}{l}\text { Initial BCVA in logMAR } \\
\text { (mean } \pm \text { SD) }\end{array}\end{array}$ & $0.98 \pm 0.82$ & $1.46 \pm 1.03$ & $0.177^{\mathrm{a}}$ \\
$\begin{array}{l}\text { Final BCVA in logMAR } \\
\text { (mean } \pm \text { SD) }\end{array}$ & $0.51 \pm 0.26$ & $0.87 \pm 0.56$ & $0.045^{\mathrm{a}}$ \\
$\begin{array}{l}\text { Macular status } \\
\text { (Attached/Detached) }\end{array}$ & $8 / 4$ & $7 / 14$ & $0.083^{\mathrm{b}}$ \\
$\begin{array}{l}\text { Retinal reattachment } \\
\text { after inferior retinotomy } \\
\text { (No. of success/No. of failure) }\end{array}$ & $12 / 0$ & $19 / 2$ & $0.523^{\mathrm{b}}$ \\
\hline
\end{tabular}

$\overline{S D}$ standard deviation, PVR proliferative vitreoretinopathy, BCVA Best-Corrected Visual Acuity

${ }^{\text {a }}$ Student t-test

${ }^{\mathrm{b}}$ Fisher exact test buckling (SB group) and 21 (63.6 \%) had undergone pars plana vitrectomy (PPV group) (Table 2). Inferior retinal redetachment occurred between 3 and 30 days after the first operation (mean 14 days). In the PPV group all underwent 23-gauge pars plana vitrectomy as the primary and secondary surgery. None of the patients had a concomitant macular hole. At the end of surgery it was reported the retina was attached in all cases.

\section{Functional outcome}

Preoperative BCVA was $1.28 \pm 0.97 \log$ MAR (median 1.00; range $0.2-3.0 \operatorname{logMAR}$ ), with significant improvement to $0.74 \pm 0.50 \log$ MAR (median 0.70; range 0.1-1.8 $\log$ MAR) (Table 3$)$ at final follow up $(p<0.003)$ with all eyes considered together. In particular, the PPV group improved from mean $1.46 \pm 1.03 \log$ Mar to $0.87 \pm 0.56 \mathrm{log}$ MAR $(p=0.024)$. The SB group changed from $0.98 \pm 0.082$ $\log$ MAR to $0.52 \pm 0.26 \log$ MAR, reaching only a trend toward significance $(p=0.057)$ (Table 4$)$. Final BCVA was better in the SB group compared with PPV group $(p=0.045)$. All patients underwent standard phacoemulsification cataract surgery and implantation of a threepiece IOL. According to our clinical opinion, no eyes had significant lens opacity despite some patients having undergone previous surgery, in particular those who had undergone PPV.

\section{Anatomical outcome}

At the last follow up, an attached retina was reported in all patients for the SB group (100\%) and 19 patients of the PPV group (90.4\%). Two patients (9.5\%) of the PPV group needed a third vitrectomy with heavy silicone oil tamponade. No intraoperative complications were observed. Postoperative complications included silicone oil in a deep anterior chamber (3 eyes in each group), untreatable hypotony ( 1 eye in the PPV group) and elevated intraocular pressure in 3 patients (2 eyes in the PPV group), which was treated successfully in all cases with topical intraocular pressure lowering drugs. Postoperative peripheral argon laser retinal photocoagulation was performed in 7 patients (3 in the PPV group) as intraoperative endolaser treatment was not fully completed. After surgery, the silicone oil was removed in all eyes, with an average interval from the last surgery of 4 months (range: 3 to 6 months). Indications for silicone oil removal were: silicone oil emulsification in the anterior chamber with 2 months of flat retina, or an attached retina for over 3 months. Silicone oil removal was as complete as possible. After silicon oil removal we observed only temporary hypotony in all cases but one in the PPV group, the patient having untreatable hypotony that required enucleation 2 years after the latest surgery due to phthisis bulbi. 
Table 3 Descriptive statistics of all participants' characteristics

\begin{tabular}{|c|c|c|c|c|c|c|c|}
\hline Characteristic & Mean & SD & Median & $25 \%$ quartile & $75 \%$ quartile & Min & Max \\
\hline Age (yrs) & 56.2 & 12.2 & 59 & 46 & 69 & 30 & 71 \\
\hline Initial BCVA (logMar) & 1.28 & 0.97 & 1 & 0.5 & 1.8 & 3.0 & 0.2 \\
\hline Final BCVA (logMar) & 0.74 & 0.50 & 0.7 & 0.4 & 0.1 & 1.8 & 0.1 \\
\hline
\end{tabular}

$S D$ standard deviation, $B C V A$ Best-Corrected Visual Acuity

\section{Discussion}

Advances in surgical techniques have significantly improved anatomical success rates for rhegmatogenous RD. Thus, current retinal surgery can offer favourable outcomes after RD, with a general success rate of up to $94 \%[7,30]$. However, the primary success rate of PPV surgery in patients with a complex RD was shown to fall as low as $74 \%$ [31], despite the fact that PPV for RD has been improved in recent decades by the use of perfluorocarbon liquids, endolaser treatment and wide-angle viewing systems. [25, 32-36] It has been shown that PVR is the most common cause of recurrent RD after surgical repair of rhegmatogenous RD and occurs in 5-11\% of patients [37-40]. Furthermore, it was previously reported that $86 \%$ of eyes with recurrent RD after vitrectomy have a component of anterior PVR [7] and eyes with anterior PVR have poorer surgical prognosis than those with posterior PVR [15, 41, 42]. Consequently, several types of complicated $\mathrm{RD}$ can be refractory to treatment and extensive peripheral retinotomy is required $[43,44]$. However, due to the high risk of complications and generally poor functional results a relaxing retinotomy is rarely advised as a primary procedure but should be considered when complex PVR is present $[35,45]$. In this study we explored anatomical and functional outcomes of 33 phakic eyes with inferior retinal redetachment and grade C PVR, with previous PPV or SB as primary treatment for inferior RD. All patients underwent PPV with $180^{\circ}$ inferior retinotomy and silicone oil tamponade (1000 centistokes) combined with phacoemulsification and IOL implantation with good anatomical results. In particular, the SB group reached $100 \%$ retinal reattachment vs $90.4 \%$ in the PPV group. In our cohort all eyes underwent a phacoemulsification with IOL to ensure radical anterior vitreous base dissection to directly release anterior vitreous traction, and reduce vitreous scaffolding for potential

Table 4 Changes of BCVA after inferior retinotomy

\begin{tabular}{llll}
\hline Surgical technique & $\begin{array}{l}\text { Initial BCVA } \\
\text { mean } \pm \text { SD }\end{array}$ & $\begin{array}{l}\text { Final BCVA } \\
\text { mean } \pm \text { SD }\end{array}$ & $P^{*}$ \\
\hline SB & $0.98 \pm 0.82$ & $0.52 \pm 0.26$ & 0.057 \\
PPV & $1.46 \pm 1.03$ & $0.87 \pm 0.56$ & 0.024 \\
SB + PPV & $1.28 \pm 0.97$ & $0.74 \pm 0.50$ & 0.003 \\
\hline
\end{tabular}

$B C V A$ Best-Corrected Visual Acuity, SD Standard deviation, SB Scleral Buckling, $P P V$ pars plana vitrectomy

*Assessed with Student paired t-test proliferative tissue [25]. Moreover an extensive inferior retinotomy was required due to the recurrent inferior detachment along with the presence of high grade PVR and retina folds. In our opinion, having a large circumferential retinotomy is beneficial in cases of recurrent inferior $\mathrm{RD}$ where vitreous remnants and the presence of high grade PVR increases the probability of having multiple small retinal breaks (sometimes undetected). We speculate that, with high grade PVR, the coexistence of multiple tiny close retinal breaks is possible. In this scenario, the tractive forces responsible for these retinal holes are not localized in a single point but spread throughout a diffuse area. We believe that in this case we should avoid treating these as multiple single tears, and perform a relaxing retinotomy (obtaining a single larger tear with a continuous linear shape) to reduce all traction forces due to the PVR. In our cohort, retinotomies were 180 degrees wide, reflecting not only the severity of the retinal disease but also to obtain a good silicon oil tamponade of the ends of the retinotomy when the patient was in the upright position [46]. Although in our groups the difference in reattachment rate is not statistically significant, we speculate that the better anatomical results in the SB group may be due to an additive effect of the buckling to the inferior RD, supporting the inadequate effect of the intraocular tamponade for inferior RD.

In a previous published study, Quiram et al. [25] reported that in cases of retinectomy, a phacoemulsification with IOL implant is mandatory in order to perform anterior vitreous base dissection. In their study, both silicone oil tamponade and radical anterior base dissection with lens removal were associated with significantly better anatomical outcomes and this is in line with our results. In contrast, in their report authors did not find any significant improvement in anatomical success when scleral buckle was associated to an inferior retinotomy. However, retinectomy was not standardized at 180 degrees but ranged from a few clock hours to $360^{\circ}$ with low repeatability of the results along with different surgeons carrying out the procedures. Additionally in their cohort, a mean of 1.8 previous surgical procedures (range 1 to 5 ) were performed, compared to our study population where all eyes underwent a single previous RD surgical repair.

Adelman et al. [47] in the first report of "European Vitreo-Retinal Society Retinal Detachment Study", stated 
that a scleral buckle can offer a better anatomic results compared to PPV in phakic eyes with uncomplicated RD. The current study highlighted how this can be noted even for complicated RD where the SB can offer good support to the inferior sclera with better anatomical results. In the second "European Vitreo-Retinal Society Retinal Detachment" [48] authors analysed results for complicated RD surgery (with grade C PVR). They concluded that relaxing retinotomy could lead to significantly higher failure rates. However, the same authors specify that their findings about retinotomy should be interpreted with caution. Our results can therefore contribute as new data to revaluate the use of relaxing retinotomy, especially in cases of recurrent $\mathrm{RD}$ after primary SB procedure. In addition, our results are consistent with data published by Tseng et al. [34] demonstrating that when silicone oil is used as a postoperative tamponade in eyes with extensive inferior pathology, the placement of an inferior retinotomy may improve anatomical results. However our study is limited by its retrospective nature and the relatively small number of subjects in each subgroup. The small sample size of our study makes it difficult to establish evidence, but we speculate that our results can help clinicians consider scleral buckle surgery (when possible) in cases of primary inferior RD for phakic eyes in an era where the PPV approach has become more popular. Furthermore, we acknowledge that our results about visual acuity should be interpreted with caution. We cannot definitively attribute the improvement of visual acuity only to retinal status as it is difficult to affirm that we performed a clear lens extraction rather then a cataract surgery. In addition, despite the fact that, no statistically significant difference between the two groups were found in terms of retinal status, macula detachment was reported in 4 eyes out of 12 in the SB group and in 14 out of 21 in the PPV group. This data can explain the overall improvement in visual acuity at baseline and post-operatively in the SB group. Nevertheless, the study has several strengths, including the single surgeon performing the surgery, the long follow-up interval, the homogeneous subset of RDs and lens status.

\section{Conclusion}

The present study re-enforces the value of relaxing retinotomy incisions in recurrent RD with grade C PVR, and does not support the view that relaxing retinotomies contribute to unfavourable anatomical outcomes in vitrectomy when performed by an expert surgeon. On the contrary, this study suggests that aggressive surgical management, in the setting of inferior retinal redetachment with complete traction relief thorough retinotomy, results in a high rate of successful reattachment, especially in eyes with pre-existing SB supporting inferior retinal breaks and receiving a silicone oil tamponade.

\section{Abbreviations}

PVR: proliferative vitreoretinopathy; SB: scleral buckling; PPV: pars plana vitrectomy; RD: retinal detachment; VA: visual acuity; logMAR: logarithm of the minimum angle of resolution; BCVA: Best-corrected visual acuity;

WHO: World Health Organization; IOL: intraocular lens; SD: standard deviation.

\section{Competing interest}

The authors declare that they have no competing interests.

\section{Authors' contributions}

Design of the study (RM, FA, CN); conduct of the study (RM, FA, EC, EDC, $A C, C N)$; data collection (RM, FA, EC, EDC, AC); analysis of data (RM, FA, EC, $E D C, A C, C N)$; interpretation of the data (RM, FA, CN); preparation of manuscript (RM, FA, EC, EDC); critical review and final approval of the manuscript (RM, FA, EC, EDC, AC, CN).

\section{Funding statement}

none

Received: 25 July 2015 Accepted: 2 December 2015

Published online: 09 December 2015

\section{References}

1. Machemer R. Cutting of the retina: a means of therapy for retinal reattachment (author's transl). Klin Monbl Augenheilkd. 1979;175(5):597-601.

2. Machemer R, McCuen 2nd BW, de Juan Jr E. Relaxing retinotomies and retinectomies. Am J Ophthalmol. 1986;102(1):7-12.

3. McCuen 2nd BW, Landers 3rd MB, Machemer R. The use of silicone oil following failed vitrectomy for retinal detachment with advanced proliferative vitreoretinopathy. Ophthalmology. 1985;92(8):1029-34.

4. Yeo JH, Glaser BM, Michels RG. Silicone oil in the treatment of complicated retinal detachments. Ophthalmology. 1987;94(9):1109-13.

5. Heremans L, Weyler J, Pertile G, Zivojnovic R, Claes C. Silicone oil tamponade in the vitreoretinal surgery. Bull Soc Belge Ophtalmol. 1999;273:105-10.

6. Lewis H, Aaberg TM. Anterior proliferative vitreoretinopathy. Am J Ophthalmol. 1988;105(3):277-84

7. Aaberg TM. Management of anterior and posterior proliferative vitreoretinopathy. XLV. Edward Jackson memorial lecture. Am J Ophthalmol. 1988;106(5):519-32.

8. Federman $J \mathrm{~L}$, Schubert HD. Complications associated with the use of silicone oil in 150 eyes after retina-vitreous surgery. Ophthalmology. 1988;95(7):870-6.

9. Morse LS, McCuen 2nd BW, Machemer R. Relaxing retinotomies. Analysis of anatomic and visual results. Ophthalmology. 1990;97(5):642-7. discussion 647-648.

10. Han DP, Lewis MT, Kuhn EM, Abrams GW, Mieler WF, Williams GA, et al. Relaxing retinotomies and retinectomies. Surgical results and predictors of visual outcome. Arch Ophthalmol. 1990;108(5):694-7.

11. Federman JL, Eagle Jr RC. Extensive peripheral retinectomy combined with posterior 360 degrees retinotomy for retinal reattachment in advanced proliferative vitreoretinopathy cases. Ophthalmology. 1990;97(10):1305-20.

12. Hutton WL, Azen SP, Blumenkranz MS, Lai MY, McCuen BW, Han DP, et al. The effects of silicone oil removal. Silicone Study Report 6. Arch Ophthalmol. 1994;112(6):778-85.

13. Blumenkranz MS, Azen SP, Aaberg T, Boone DC, Lewis H, Radtke N, et al. Relaxing retinotomy with silicone oil or long-acting gas in eyes with severe proliferative vitreoretinopathy. Silicone Study Report 5. The Silicone Study Group. Am J Ophthalmol. 1993;116(5):557-64.

14. Barr CC, Lai MY, Lean JS, Linton KL, Trese M, Abrams G, et al. Postoperative intraocular pressure abnormalities in the Silicone Study. Silicone Study Report 4. Ophthalmology. 1993;100(11):1629-35.

15. Diddie KR, Azen SP, Freeman HM, Boone DC, Aaberg TM, Lewis H, et al. Anterior proliferative vitreoretinopathy in the silicone study. Silicone Study Report Number 10. Ophthalmology. 1996;103(7):1092-9.

16. Sigler EJ, Randolph JC, Calzada JI, Charles S. Pars plana vitrectomy with medium-term postoperative perfluoro-N-octane for recurrent inferior retinal detachment complicated by advanced proliferative vitreoretinopathy. Retina. 2013;33(4):791-7.

17. Charles S, Randolph JC, Sigler EJ. Pars plana vitrectomy reoperation without removing silicone oil. Retina. 2012;32(8):1664-5. 
18. Kotoulas A, Symeonidis C, Kalantzis G, Droutsas K, Koutsandrea C, Georgalas I. Total extrusion of a silicone encircling band through the muscle insertions presenting as orbital cellulitis. Orbit. 2014;33(4):308-10.

19. Yoshida A, Feke GT, Green GJ, Goger DG, Matsuhashi M, Jalkh AE, et al. Retinal circulatory changes after scleral buckling procedures. Am J Ophthalmol. 1983;95(2):182-8.

20. Goezinne F, La Heij EC, Berendschot TT, Tahzib NG, Cals DW, Liem AT, et al Anterior chamber depth is significantly decreased after scleral buckling surgery. Ophthalmology. 2010;117(1):79-85.

21. Machemer R, Aaberg TM, Freeman HM, Irvine AR, Lean JS, Michels RM. An updated classification of retinal detachment with proliferative vitreoretinopathy. Am J Ophthalmol. 1991;112(2):159-65.

22. Ricci F, Cedrone C, Cerulli L. Standardized measurement of visual acuity. Ophthalmic Epidemiol. 1998;5(1):41-53.

23. Holladay JT. Proper method for calculating average visual acuity. J Refract Surg. 1997;13(4):388-91.

24. World Health Organization. International statistical classification of diseases and related health problems. 10th revision. Geneve; WHO: 1992. p. 456-457.

25. Quiram PA, Gonzales CR, Hu W, Gupta A, Yoshizumi MO, Kreiger AE, et al. Outcomes of vitrectomy with inferior retinectomy in patients with recurrent rhegmatogenous retinal detachments and proliferative vitreoretinopathy. Ophthalmology. 2006;113(11):2041-7.

26. Scott IU, Flynn Jr HW, Murray TG, Feuer WJ. Outcomes of surgery for retinal detachment associated with proliferative vitreoretinopathy using perfluoron-octane: a multicenter study. Am J Ophthalmol. 2003;136(3):454-63.

27. Bourke RD, Cooling RJ. Vascular consequences of retinectomy. Arch Ophthalmol. 1996;114(2):155-60.

28. Jackson TL, Thiagarajan M, Murthy R, Snead MP, Wong D, Williamson TH. Pupil block glaucoma in phakic and pseudophakic patients after vitrectomy with silicone oil injection. Am J Ophthalmol. 2001;132(3):414-6.

29. Pavlidis M, Scharioth G, de Ortueta D, Baatz H. Iridolenticular block in heavy silicone oil tamponade. Retina. 2010;30(3):516-20.

30. Brazitikos PD, Androudi S, Christen WG, Stangos NT. Primary pars plana vitrectomy versus scleral buckle surgery for the treatment of pseudophakic retinal detachment: a randomized clinical trial. Retina. 2005;25(8):957-64.

31. Sodhi A, Leung LS, Do DV, Gower EW, Schein OD, Handa JT. Recent trends in the management of rhegmatogenous retinal detachment. Surv Ophthalmol. 2008;53(1):50-67.

32. Jonas JB, Knorr HL, Rank RM, Budde WM. Retinal redetachment after removal of intraocular silicone oil tamponade. Br J Ophthalmol. 2001;85(10):1203-7.

33. Bui Quoc E, Bernard A, Azan F, Renard G, Chauvaud D. [Results of treating rhegmatogenous retinal detachment with vitrectomy and silicone oil tamponade]. J Fr Ophtalmol. 2005;28(9):944-52.

34. Tseng JJ, Barile GR, Schiff WM, Akar Y, Vidne-Hay O, Chang S. Influence of relaxing retinotomy on surgical outcomes in proliferative vitreoretinopathy Am J Ophthalmol. 2005;140(4):628-36.

35. Grigoropoulos VG, Benson S, Bunce C, Charteris DG. Functional outcome and prognostic factors in 304 eyes managed by retinectomy. Graefes Arch Clin Exp Ophthalmol. 2007;245(5):641-9.

36. Schiff WM, Hwang JC, Ober MD, Olson JL, Dhrami-Gavazi E, Barile GR, et al. Safety and efficacy assessment of chimeric ribozyme to proliferating cell nuclear antigen to prevent recurrence of proliferative vitreoretinopathy. Arch Ophthalmol. 2007;125(9):1161-7.

37. Rachal WF, Burton TC. Changing concepts of failures after retinal detachment surgery. Arch Ophthalmol. 1979;97(3):480-3.

38. Speicher MA, Fu AD, Martin JP, von Fricken MA. Primary vitrectomy alone for repair of retinal detachments following cataract surgery. Retina. 2000;20(5):459-64.

39. Mancino R, Ciuffoletti E, Martucci A, Aiello F, Cedrone C, Cerulli L, et al. Anatomical and functional results of macular hole retinal detachment surgery in patients with high myopia and posterior staphyloma treated with perfluoropropane gas or silicone oil. Retina. 2013;33(3):586-92.

40. Girard P, Mimoun G, Karpouzas I, Montefiore G. Clinical risk factors for proliferative vitreoretinopathy after retinal detachment surgery. Retina. 1994;14(5):417-24.

41. Lewis H, Aaberg TM, Abrams GW. Causes of failure after initial vitreoretinal surgery for severe proliferative vitreoretinopathy. Am J Ophthalmol. 1991;111(1):8-14.

42. Lewis $\mathrm{H}$, Aaberg TM. Causes of failure after repeat vitreoretinal surgery for recurrent proliferative vitreoretinopathy. Am J Ophthalmol. 1991;111(1):15-9.
43. Lu L, Gao R, Lin X. TThe application of retinotomy and retinectomy for complicated retinal detachment]. Yan Ke Xue Bao. 1998;14(2):94-6.

44. Shalaby KA. Relaxing retinotomies and retinectomies in the management of retinal detachment with severe proliferative vitreoretinopathy (PVR). Clin Ophthalmol. 2010;4:1107-14.

45. Kolomeyer AM, Grigorian RA, Mostafavi D, Bhagat N, Zarbin MA. 360 degrees retinectomy for the treatment of complex retinal detachment. Retina. 2011;31(2):266-74.

46. Bovey EH, De Ancos E, Gonvers M. Retinotomies of 180 degrees or more. Retina. 1995:15(5):394-8.

47. Adelman RA, Parnes AJ, Ducournau D. Strategy for the management of uncomplicated retinal detachments: the European vitreo-retinal society retinal detachment study report 1. Ophthalmology. 2013;120(9):1804-8.

48. Adelman RA, Parnes AJ, Sipperley JO, Ducournau D. Strategy for the management of complex retinal detachments: the European vitreo-retinal society retinal detachment study report 2. Ophthalmology. 2013;120(9):1809-13.

\section{Submit your next manuscript to BioMed Central and we will help you at every step:}

- We accept pre-submission inquiries

- Our selector tool helps you to find the most relevant journal

- We provide round the clock customer support

- Convenient online submission

- Thorough peer review

- Inclusion in PubMed and all major indexing services

- Maximum visibility for your research

Submit your manuscript at www.biomedcentral.com/submit 